Visítanos en:

https://journal.poligran.edu.co/index.php/poliantea

\section{Alcances y limitaciones en el conocimiento del trastorno límite}

\author{
Leidy Tatiana Castañeda Quirama \\ Icastaneda@poligran.edu.co
}

Institución Universitaria Politécnico Grancolombiano,

Programa de Psicología Medellín

La estrategia llevada a cabo para el desarrollo del Proyecto de Investigación Formativa (PIF) en el curso de psicopatología, fue la revisión no sistemática acerca de los Trastornos de personalidad, dada la complejidad clínica que representa la evaluación, diagnóstico e intervención de este tipo de patologías. Se sugiere esta metodología de investigación, ya que permite identificar los hallazgos de estudios elaborados con anterioridad, construir hipótesis iniciales; conocer las aproximaciones teóricas; rastrear preguntas y objetivos de investigación; conocer los procedimientos empleados en el estudio del tema (metodologías); establecer semejanzas y diferencias entre los trabajos y precisar limitaciones metodológicas o en el conocimiento. Lo anterior, genera en el estudiante competencias para aproximarse a la investigación a partir de la elaboración de preguntas direccionadas a conocer los alcances y limitaciones existentes sobre un tema (en este caso el trastorno límite de la personalidad), y de este modo despertar su interés en la formulación de discusiones y conclusiones que permitan dar cuenta de la importancia que merece la formulación de proyectos investigativos que permitan llenar los vacíos teóricos existentes, ya que de este modo, se contribuye al conocimiento de los distintos trastornos, desde métodos de evaluación y diagnostico que favorezcan el empleo de planes de tratamiento más eficaces.
Recepción: $\quad 01.2020$

Aceptación: $\quad 03.2020$ 